\title{
Engineering composite materials for the cotton processing industry
}

\author{
Nodira Abed $^{1 *}$, Olim Eshkobilov², Giyas Gulyamov ${ }^{1}$, Malokhat Tuhtasheva ${ }^{1}$ \\ ${ }^{1}$ State Unitary Enterprise "Fan va tarakkiyot" at Tashkent state technical university named after Islom \\ Karimov \\ ${ }^{2}$ Karshi Engineering-Economic Institute, Karshi, Uzbekistan
}

\begin{abstract}
Experimental studies have been carried out to study the effect of various fillers on the physicomechanical and tribotechnical properties of the compositions, and the optimal filler contents have been established, which ensure the best properties of polyethylene, polypropylene, polystyrol and polyamide structural composite materials. The principle of design of shock-resistant, antifriction and antifriction-wear-resistant polyethylene, polypropylene, polystyrol and polyamide structural composite materials is proposed. Highly efficient structural composite materials for functional purposes have been developed on the basis of thermoplastic polymers and fillers of various structures and natures, which have sufficiently high strength and tribotechnical characteristics and have found application in the working bodies of cotton machines and mechanisms of the cotton processing industry operating under conditions of friction and wear.
\end{abstract}

\section{Introduction}

In modern high technology, structural composite materials are widely used, the creation of which is due to the need for new materials in various branches of mechanical engineering, including the cotton ginning industry.

At present, for the manufacture of parts of rubbing pairs of working bodies of machines and mechanisms, it is required to develop new structural composite polymeric materials for functional purposes, intended for operation under friction conditions, when they interact with raw cotton. This determined the basic requirements for them. Such materials should have high impact resistance, low coefficient of friction, minimal wear when rubbing with pulp (raw cotton). In this regard, it is advisable to develop scientific principles that are necessary, as initial data, when creating shock-resistant (UP), antifriction (A) and antifriction-wear-resistant (AI) composite polymer materials (CPM).

\section{Method}

There are the principles of creating shock-resistant, antifriction and antifriction-wearresistant composite polymer materials. For impact-resistant materials, a necessary property

\footnotetext{
*Corresponding author: polegon11@mail.ru
} 
is high impact resistance (IR), for antifriction composite material (ACM) - a low coefficient of friction with raw cotton, for antifriction-wear-resistant composite materials (AWRCM) a low coefficient of friction and low wear of the material when rubbed with cotton raw.

Proceeding from the fact that the friction of polymeric materials with raw cotton has a molecular-mechanoelectrical nature, the obtained research results will allow to purposefully change and regulate the properties of materials, ensuring their compliance with the requirements for composite polymeric materials working in interaction with raw cotton.

Of the materials selected for research, polyamide (PA) has the best antifriction properties. They can serve as a matrix of composite materials for antifriction purposes and high-impact polystyrene (HIPS) has the best impact strength and hardness.

When choosing a filler for impact-resistant composite materials (IRCM), it is necessary to consider its effect on specific viscosity. For high-impact composite materials based on PA and HIPS, the best fillers are fiberglass, cotton lint, and wollastonite. For ACM, it is necessary to consider its effect on the coefficient of friction in a wide range of load, speed, moisture, contamination and grade, as well as the preservation of the quality indicators of raw cotton. The best fillers for the above materials are fillers - carbon black, graphite, talc, kaolin, and wollastonite.

AWRCM must meet the requirements of the minimum coefficient of friction and the minimum intensity of wear. As fillers for such materials, it is advisable to use asbestos, graphite, fiberglass (FG), cotton lint (CL), iron powder, cement, copper powder, kaolin, talc, soot, and wollastonite.

Thus, the scientific principles for creating polymer composite materials have been developed, which can be used in the development of shock-resistant, antifriction and antifriction-wear-resistant polymer composite materials based on local raw materials and industrial waste.

\section{Materials and Methods}

\subsection{Impact-resistant, antifriction and anti-friction-wear-resistant polymer composite materials}

The modern level of development of composite polymer materials (CPM) allows you to create unique materials that are efficient in extreme conditions at low and high temperatures, pressures, aggressive and abrasive environments. The trend in the development of this area is the creation of highly filled, reinforced and especially durable CPM with adjustable performance indicators for structural, special and multifunctional purposes.

However, the existing polymer materials and compositions based on them are not yet widely used in the working bodies of machines and mechanisms of various branches of mechanical engineering, in particular, in equipment for the cotton processing industry due to the lack of developments in the creation of reliable shock-resistant, wear-resistant, antifriction and antifriction-wear-resistant composite polymer materials based on local resources and effective technology for their production, as well as the manufacture of engineering products and parts for construction and special purposes from them.

At present, for the manufacture of parts of rubbing pairs of working bodies of machines and mechanisms, it is required to develop new composite polymeric materials for functional purposes, designed to work under friction conditions when they interact with raw cotton. This led to the development of basic requirements for them. Such materials should have high impact resistance, low coefficient of friction, minimal wear when rubbing with pulp (raw cotton). 
As can be seen from figures 1, 2, 3, 4, the properties of composite polymer materials fully meet the functional requirements for the material of parts of rubbing pairs of working bodies of machines and mechanisms of the cotton complex; they meet the requirements for the materials of the heads of working bodies, the main of which are the technological and economic efficiency of the material used, effective reduction of damage to cotton fiber and seeds, elimination of the accumulation of static electricity, the formation of windings of the fiber on the surface of the pegs and sparks upon impact with solid bodies in the raw cotton.

The developed composite polymer materials were used to manufacture parts of rubbing pairs of working bodies of a mobile cotton loader of the HPP brand, a tunnelling machine of the OBT brand, a cotton riot puller of the RBD brand and a pneumatic mechanical cotton picker used at procurement points and cotton refineries during acceptance, transportation, disassembly and supply raw cotton into subsequent technological units (Figure 5).

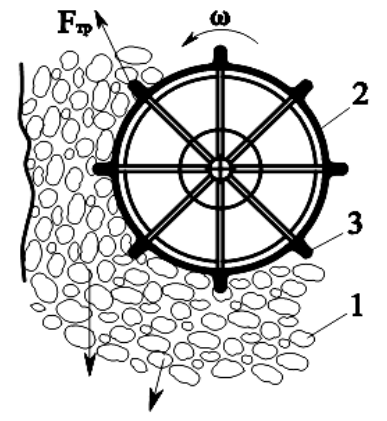

Fig.1. Diagram of interaction of the working body of a cotton picker of the RBD brand and a pneumomechanical picker of a raw cotton feeder;

$F_{t p}$ is frictional force of splitting machine made of KPM with raw cotton; $\omega$ is number of revolutions of the working body of the RBD or RP. 1 is raw cotton; 2 is cutter; 3 is pegs.

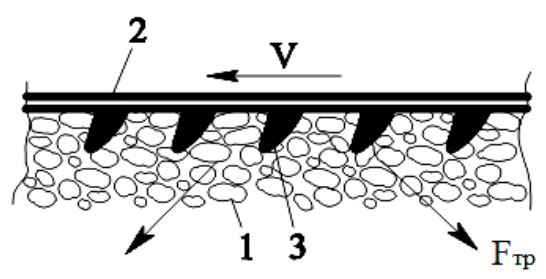

Fig.3. Scheme of interaction of the working body of the OBT brand tunnelling machine with raw cotton; $F_{\text {tp }}$ is force of friction of a splitting machine made of KPM with raw cotton; $\mathrm{V}$ is speed of the working body. 1 is raw cotton; 2 is tape; 3 is pegs.

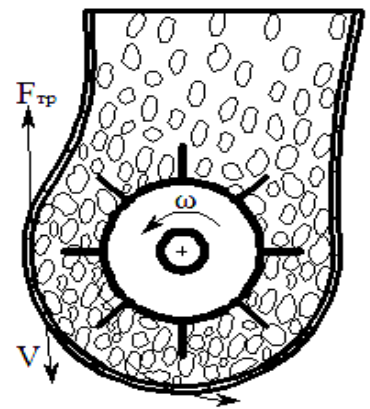

Fig.2. Scheme of interaction of the working bodies of the fine litter cleaner with raw cotton; $F_{t p}$ is frictional force of splitting machine made of KPM with raw cotton; $\mathrm{V}$ is the sliding speed; $\omega$ is the number of revolutions of the working body of the RBD or RP.

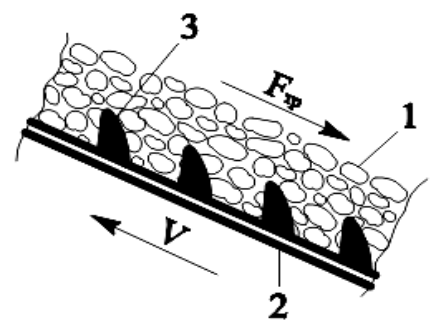

Fig.4. Scheme of interaction of the working body of the mobile cotton loader of the HPP brand; $F_{t p}$ is frictional force of splitting machine made of KPM with raw cotton; $\mathrm{V}$ is speed of the working body. 1 is raw cotton; 2 is tape; 3 is pegs. 


\section{Results and Discussion}

The pegs of the working body of a mobile cotton loader is a gripping element made in the form of a rod with a spherical rounding in the head part, which is made of elastic antifriction-wear-resistant antistatic-heat-conducting composite polymer materials with a trapezoidal profile in cross-section and placed on the base. At the same time, its gripping surface is located at an angle to the base, and in the base between the profile stiffeners, a hole is made for a bolted connection and a recess with a radius of $40 \mathrm{~mm}$ (fig. 5).

The spherical curvature at the head of the splitter with a radius of $R_{1}=10 \mathrm{~mm}$ facilitates its penetration into the mass of raw cotton.

The radius of curvature $(R)$ of the splitter is $270-272 \mathrm{~mm}$, the tilt angle $\left(\varphi_{p}\right)$ of the splitter to the surface of the tape of the working body is $65-70^{\circ}$, and the angle between the lateral faces $\left(\alpha_{\mathrm{p}}\right)$ of the splitter is $20-25^{\circ}$. The specified parameters ensure the introduction of the splitter into the mass of raw cotton, improving its grasping ability, reliability, and work efficiency.

The pegs are assembled in the working body as follows. The pegs made of composite polymer materials 1 are fixed on the base, which is used as a plastic or metal longitudinal strip, and on the tape of the working body using bolted connections (bolt, nut, washer). Depending on the number of pegs fixed on the longitudinal strip of the tape, the pitch between the longitudinal strips is chosen equal to $450-500 \mathrm{~mm}$. Longitudinal strips with pegs on the surface of the working body are staggered to ensure the uniform withdrawal of fibrous material (raw cotton).
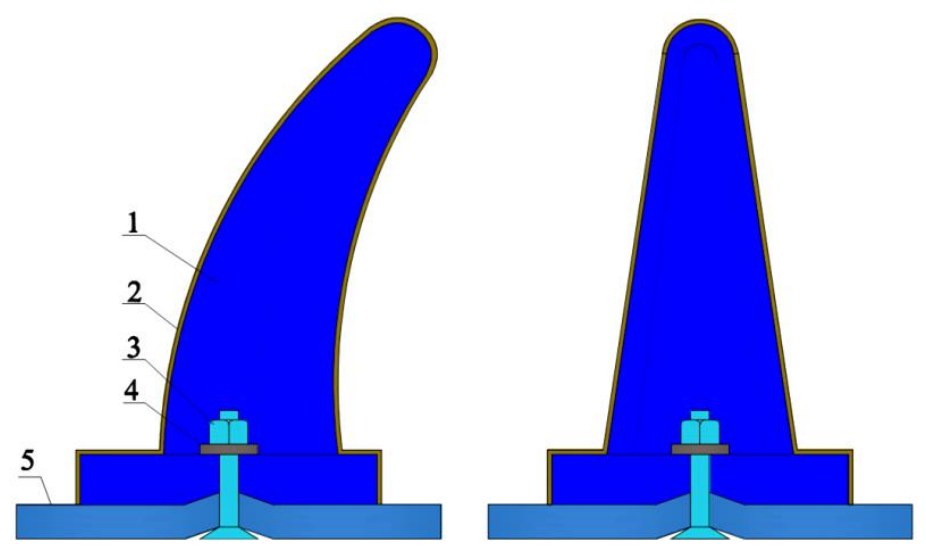

Fig. 5. Peg of the working body of the mobile cotton loader of the HPP brand. 1 is peg, 2 is composite polymer material, 3 is bolt-nut M8, 4 is washer, 5 is rubberized band of the working body.

Splitting with a trapezoidal profile in cross-section with side ribs allows increasing the rigidity and stability of its structure without increasing the size of the head of the splitter, which would adversely affect the ability of the splitter to penetrate into the mass of raw cotton. The splitting sections made of shock-resistant, antifriction, wear-resistant and antifriction-wear-resistant composite materials are thickened by $40-50 \%$ compared to metal ones; the value of permissible stresses is also reduced by $25-30 \%$. Since it is impossible to obtain the proper strength with a uniform cross-section of the peg, the peg is inevitably subjected to bending and impact, leading to a sharp decrease in local strength and breaks.

The peg of the working body of the cotton riot separator is made in the form of a rod having the shape of a truncated cone, bent along the radius of curvature in the direction of rotation of the working body of the milling type (Figure 6). 

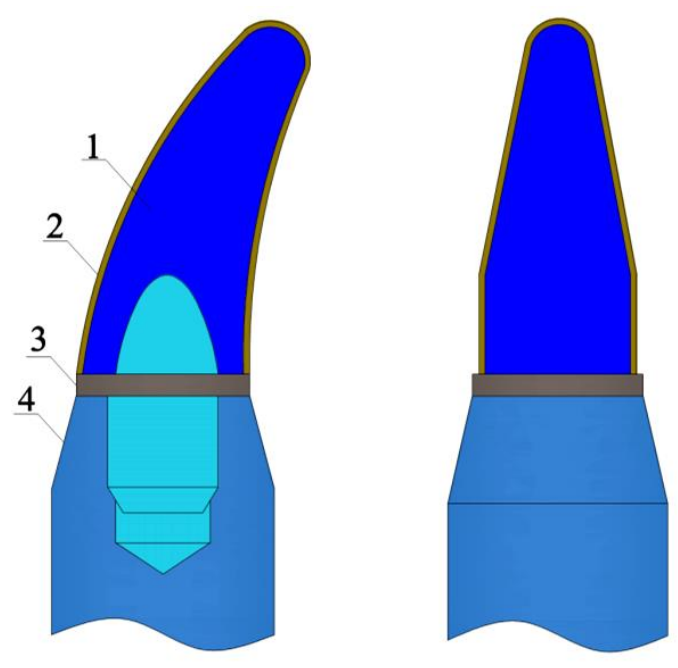

Fig. 6. The head of the working body of the separator of cotton riots of the RBD brand. 1 is peg, 2 is composite polymer material, 3 is washer, 4 is milling-type working body.

The radius of curvature is $70-75 \mathrm{~mm}$. The pegs are assembled in the working body as follows. The tuning pegs with M18 thread are screwed onto the cutter pipe of the working body. When replacing the pegs, it is enough to unscrew them, and the pegs are freed from the cutter tube.

A tunnelling machine for digging and combing the edges of a cotton bundle consists of an arrow with a chain-peg working body, on the chain of which strips with pegs are fixed (Fig. 7). The lower part of the tuning peg has a fork shape with two holes for fastening to the bar using a bolt connection. This facilitates the assembly of the tuning pegs and eliminates the operations of finishing and welding the tuning pegs to the longitudinal metal strip.
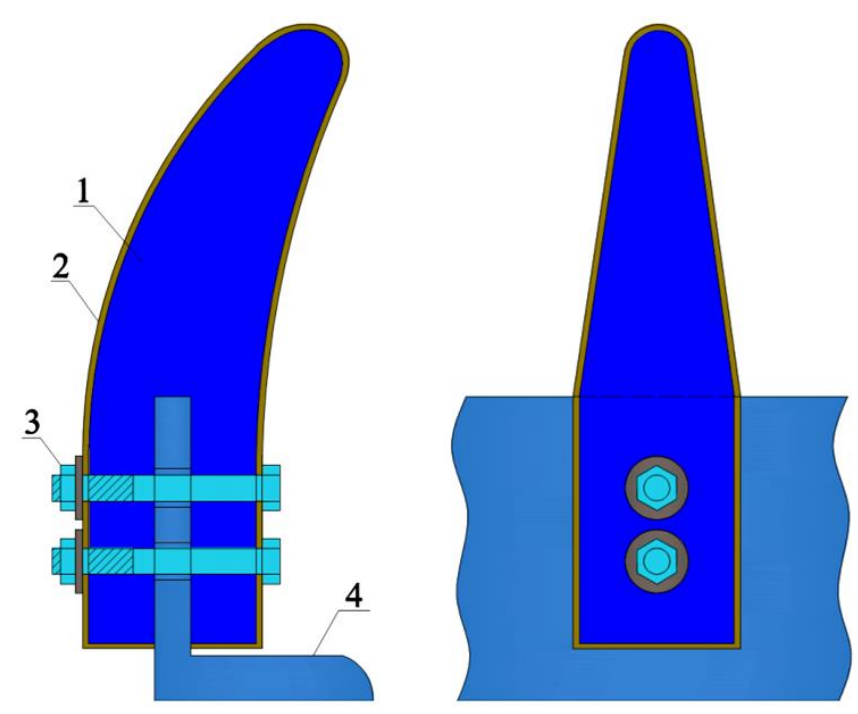

Fig. 7. Peg of the working body of the OBT tunnel machine. 1 is peg, 2 is composite polymer material, 3 is bolt-nut-washer, 4 is metal square. 
The installation of the tuning pegs in the working body of the tunnelling machine is as follows. The tuning pegs are preliminarily fixed to the longitudinal strips using bolted joints, and then, in turn, the longitudinal strips with the pegs are fixed to the working body chain. In this case, the pitch between the longitudinal strips is $350-400 \mathrm{~mm}$. When replacing the pegs, it is enough to unscrew the nuts, and the pegs are freed from the bar.

This design of the heads of the working body of a mobile cotton loader, a cotton riot picker and a tunnelling machine makes it possible to simplify and also reduce the labor intensity of installing and replacing the heads, simplifies the technology of manufacturing and assembling the working body.

The use of the developed anti-friction-wear-resistant antistatic-heat-conducting composite polymer materials as materials for parts of rubbing pairs of working bodies of cotton machines and mechanisms operating in conditions of frictional interaction with raw cotton leads to an increase in machine productivity by $12-16 \%$ and a decrease in power consumption by $7-18 \%$, damage to cotton fibers and crushing of seeds, as well as the elimination of possible ignition of raw cotton and the formation of fiber windings on the surface of the pegs.

\section{Conclusions}

In this regard, taking into account the above-developed principles of creating polymer composite materials, high-impact polystyrene compositions (HIPSC: polystyrene + carbon black + glass fiber; polystyrene + graphite + cotton lint $)$ and high-impact polyamide compositions (HIPAC: polyamide + carbon black + glass fiber; polyamide + graphite + wollastonite; polyamide + graphite + glass fiber), antifriction polyamide compositions (APAC: polyamide + wollastonite + fiberglass), anti-friction and wear-resistant polyamide compositions (WRPAC: polyamide + carbon black + talc + fiberglass) for functional purposes for machine parts and rubbing pairs mechanisms of ginning factories.

The physical and mechanical properties of the developed shock-resistant, antifriction, and antifriction-wear-resistant composite polymer materials based on thermoplastic polymers are shown in figure 8 , and their and tribotechnical properties are shown in figure 9. As a counter body, raw cotton of the C-6524 variety of the first grade was taken, and humidity $\mathrm{W}=8.2 \%$. 


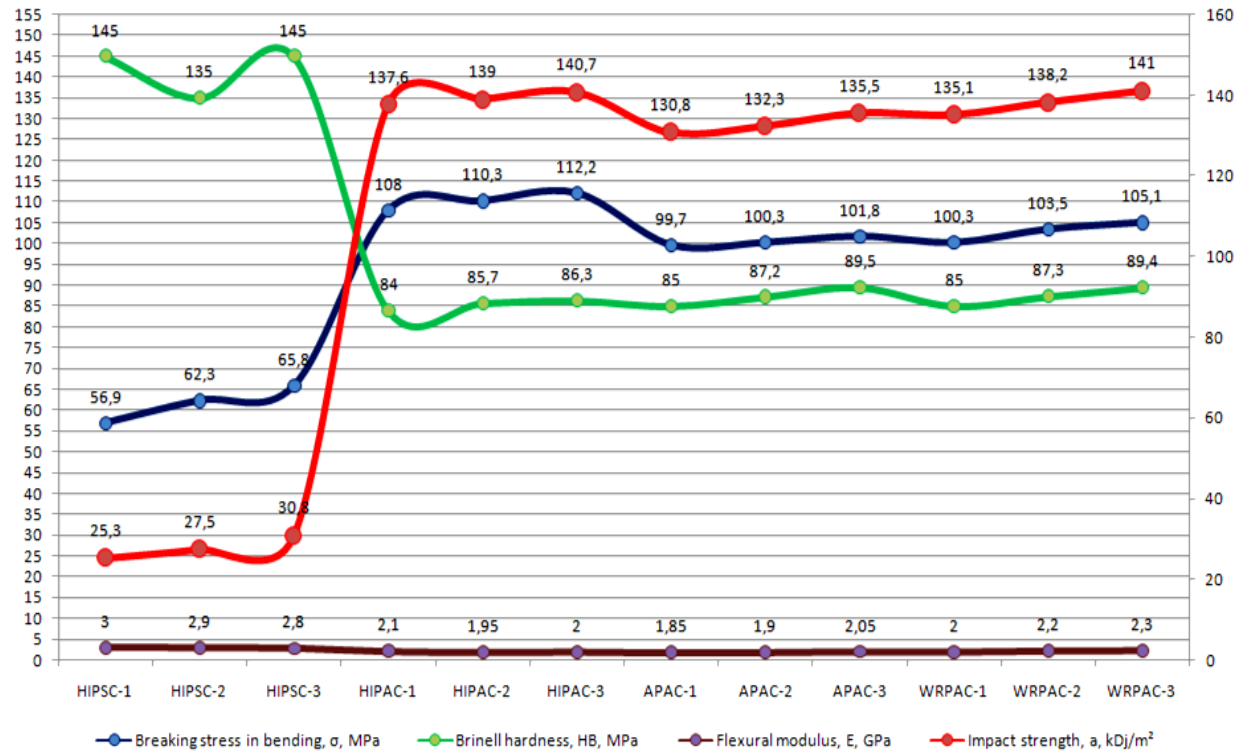

Fig. 8. Physical and mechanical properties of shock-resistant, antifriction and wear-resistant composite

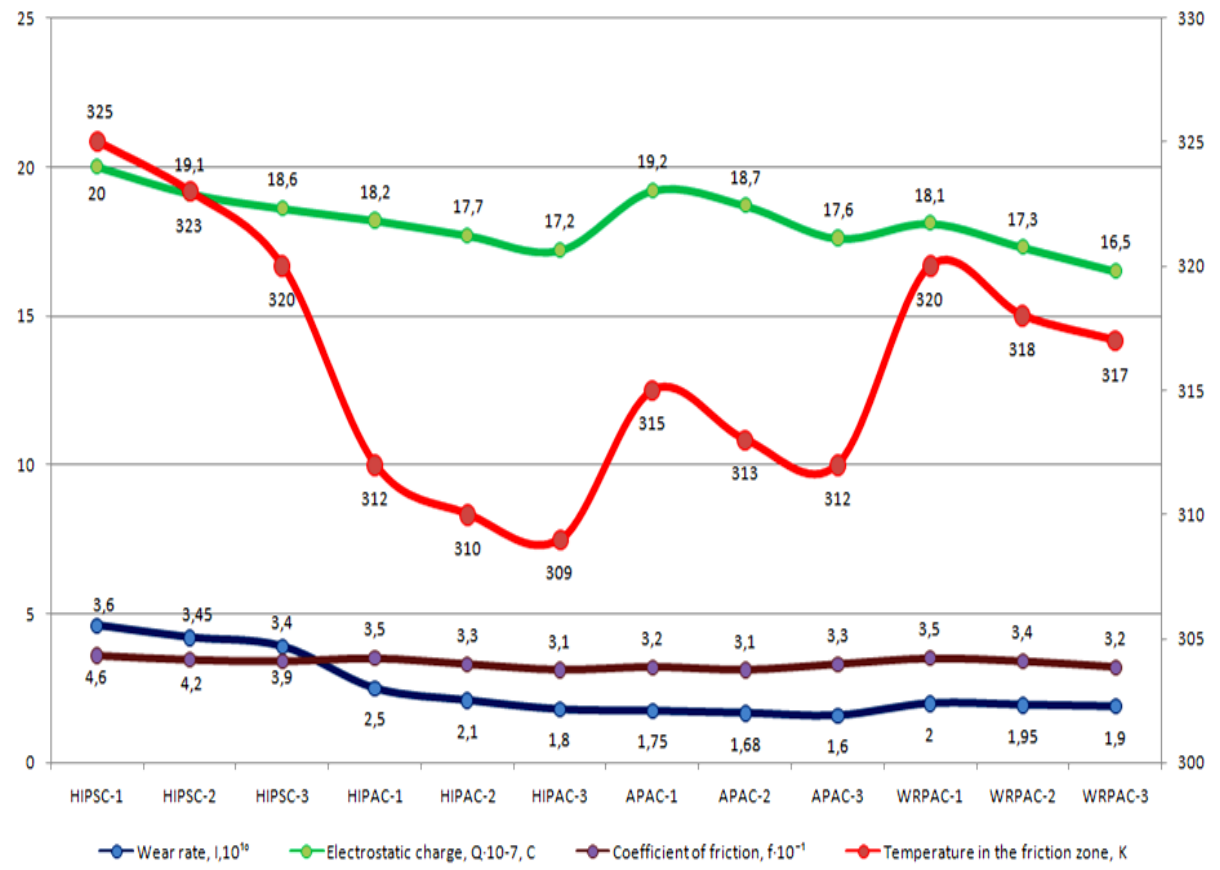

Fig. 8. Tribological properties of shock-proof, antifriction and wear-resistant composite

Note: specific pressure $P=0.01 \mathrm{MPa}$, sliding speed $V=1.5 \mathrm{~m} / \mathrm{s}$, humidity $W=8.2 \%$.

As can be seen from the data in figure 1 and 2, the developed shock-resistant, antifriction and antifriction-wear-resistant composite materials have sufficiently high physical, mechanical and tribotechnical properties and durability.

Physicomechanical and tribotechnical characteristics of the developed shock-resistant, 
antifriction and antifriction-wear-resistant composite polymer materials based on thermoplastic polymers fully meet the functional requirements for the materials of the heads of working bodies of cotton machines and mechanisms of the cotton ginning industry and can be recommended for their manufacture.

Thus, highly effective antifriction-wear-resistant functional compositions based on thermoplastic polymers have been developed, which consists in introducing a system of hybrid fillers from local raw materials and industrial waste of different structure and nature into the polymer matrix in their established optimal ratios, providing functionally important physical and mechanical, tribotechnical and operational properties of composite polymeric materials operating under conditions of interaction with raw cotton.

\section{References}

1. Negmatov S.S., Abed N.S., Gulyamov G., Eshkobilov O.Kh. Features of contact interaction of composite polymer materials with raw cotton in the process of friction. IOP Conference Series: Materials Science and Engineering, Volume 1030, VII International Scientific Conference "Integration, Partnership and Innovation in Construction Science and Education" (IPICSE 2020) 11-14th November 2020y, Tashkent, Uzbekistan. doi:10.1088/1757-899X/1030/1/012172. (2020).

2. Negmatov S.S., Abed N.S., Gulyamov G., Eshkobilov O.Kh. Investigation of the effect of temperature and electric charge on the coefficient of friction of a composite material when interacting with raw cotton, Innovative technologies, №3(39)// Karshi, 2020y. -P. 55-59.( 2020).

3. Negmatov S.S., Abed N.S., Gulyamov G., Tukhtasheva M.N., Eshkobilov O.Kh, Study of the strength properties of antifriction antistatic-heat-conducting composite materials based on polyolefins, Innovative technologies, 4 (40)// Karshi,. pp. 33-37. (2020)

4. Negmatov S.S., Gulyamov G., Eshkobilov O.Kh., Daminov L.O. Anti-friction and wear-resistant composites for automobiles and tractor construction. Automotive and tractor construction, International scientific-practical conference, Belarusian National Technical University. Byelorussia, pp 28-31.(2019)

5. Negmatov S.S., Abed N.S., Gulyamov G., Eshkobilov O.Kh. Installation and methodology for determining of antifrictional properties of antistatic-heatconducting composite polymeric materials interacting with fibrous mass (cottonraw), Technical science and innovation// Tashkent, 2.pp 20-23.( 2018)

6. Negmatov S.S., Eshkobilov O.Kh., Abed N.S., Negmatova K.S., Tulaganova V. Theoretical basics of contact interaction of machinery antifriction composite polymer materials with fibrous mass (raw cotton), Advanced Materials Research, Switzerland, pp 160-166.( 2018)

7. Abed N.S., Gulyamov G., Eshkobilov O.Kh. Methods for studying the coefficient of friction of wear of composite polymer materials based on polyolefins, International symposium on innovative scientific conference "Integration and integration of science and education" /International scientific-practical conference/ Tashkent,. -pp. 41-43. (2018).

8. Eshkobilov O.Kh. Ensuring the reliability of operation of parts and assemblies made of engineering polymer materials based on local raw materials, Modern trends in the development of the agrarian complex ,International scientific-practical conference, Caspian Research Institute of Arid Agriculture. -Solenoe Zaymishe, 1113 мау 2016y. -P. 1301-1304. (2016).

9. Negmatov S.S., Abed N.S., Gulyamov G., Eshkobilov O.Kh, Tukhtasheva M.N. 
Investigation of the physicochemical mechanism of interaction of the components of antistatic and heat-conducting polypropylene composite materials. The role of chemistry in the development of the economy of Uzbekistan /Republican scientific and practical conference/-SamSU, Samarkand, pp 67-70.(2018).

10. Negmatov S.S., Abed N.S., Gulyamov G., Eshkobilov O.Kh., Tukhtasheva M.N. Methods for studying the tribological properties of antifriction-wear-resistant antistatic-heat-conducting composite polymer materials with fibrous mass, Composite materials, №1// -Tashkent,. pp. 86-89. (2018)

11. Negmatov S.S., Abed N.S., Gulyamov G., Eshkobilov O.Kh., Tukhtasheva M.N. On the problem of developing methodological foundations of the method for studying the properties of anti-friction-wear-resistant antistatic-heat-conducting composite polymer materials operating under conditions of interaction with pulp, Composite materials, 1. Tashkent,. pp 99-100.(2018).

12. Abed N.S., Gulyamov G., Eshkobilov O.Kh. Composites based on functional thermoplastic polymer systems. Modern problems of polymer science, UzbekKazakh Symposium, Institute of Chemistry and Physics of Polymers of the Academy of Sciences of the Republic of Uzbekistan. -Tashkent,.pp 90-92. (2018)

13. Negmatov S.S., Abed N.S., Gulyamov G., Eshkobilov O.Kh. Peculiarities of the mechanism of chemical interaction of polymers with carbon-graphite fillers. Prospects for innovative development of the mining and metallurgical complex, International scientific-practical conference, Tashkent, pp 222-223.(2018).

14. Negmatov S.S., Abed N.S., Gulyamov G., Eshkobilov O.Kh., Tukhtasheva M.N. A device for determining the coefficient of friction of engineering structural materials. Prospects for innovative development of the mining and metallurgical complex /International scientific-practical conference/ Tashkent. pp 304-305.(2018).

15. Abed N.S., Gulyamov G., Eshkobilov O.Kh., Tukhtasheva M.N. Evaluation of the frictional properties of antistatic-heat-conducting composite polymer materials when interacting with raw cotton. International symposium on innovative scientific conference "Integration and integration of science and education", International scientific-practical conference, Tashkent,. pp. 39-41.(2018).

16. Negmatov S.S., Abed N.S., Gulyamov G., Eshkobilov O.Kh., Tukhtasheva M.N. Technological modes of processing of antistatic-heat-conducting antifriction-wearresistant and nanocomposite and nanocomposite polymer materials. Problems of improving the efficiency of modern production and energy and resource conservation /International scientific-practical conference/ Andijan, 3-4 oktober 2018y. pp. 45-48. (2018)

17. Negmatov S.S., Abed N.S., Gulyamov G., Eshkobilov O.Kh. Installation for determining the antifriction properties of antistatic-heat-conducting composite polymer materials. Problems of improving the efficiency of modern production and energy and resource conservation /International scientific-practical conference/ Andijan,. pp 48-52. ( 2018).

18. Negmatov S.S., Gulyamov G., Abed N.S., Eshkobilov O.Kh., Tukhtasheva M.N. Method for determining the values of electrostatic charges and temperatures occurring in the friction zone in the tribosystem "composite-fibrous materials», Composite materials, Tashkent pp 79-81.(2019).

19. Negmatov S.S., Abed N.S., Gulyamov G., Eshkobilov O.Kh., Tukhtasheva M.N. Development of a method for determining the intensity of wear of anti-friction-wearresistant antistatic-heat-conducting composite polymer materials and coatings based on them when interacting with pulp. Composite materials, 2 Tashkenty, pp 75-77.(2019)

20. Negmatov S.S., Abed N.S., Gulyamov G., Eshkobilov O.Kh., Tukhtasheva M.N. 
Installation and method for determining the antifriction properties of antistaticheat-conducting composite polymeric materials interacting with raw cotton, Mechanic problems, 2, Tashkent. pp 66-70. (2019).

21. Negmatov S.S., Abed N.S., Gulyamov G., Eshkobilov O.Kh. Investigation of the influence of carbon-graphite and fibrous fillers on the antifriction properties of polyolefins, Innovative technologies, 3 (35). Karshi. pp 22-26. (2019).

22. Negmatov S.S., Gulyamov G., Abed N.S., Eshkobilov O.Kh., Tukhtasheva M.N. Antifriction-wear-resistant composite polymer materials for engineering. Integrated innovative development of Zarafshan region: achievements, chalenges and prospects, International scientific-practical conference, Navoiy, 27-28 november 2019y. pp 262-265.(2019).

23. Negmatov S.S., Gulyamov G., Ulmasov T.U., Abed N.S., Eshkobilov O.Kh., Saidova M.M., Bozorboyev Sh.A., Tukhtasheva M.N., Eminov Sh. Investigation of the technological process of contact interaction of surfaces of metal working bodies of machines with raw cotton. Composite materials, 1. Tashkent, pp 120-124.(2020).

24. Tukhtasheva M.N., Negmatov S.S., Gulyamov G., Ulmasov. T.U., Abed N.S., Eshkobilov O.Kh., Saidova M.M., Eminov Sh., Bozorboyev Sh.A., Navruzov F.M. Experimental study of the effect of fibrous fillers on antifriction, wear-resistant, technological properties of polyolefins. Composite materials, 1. Tashkent, pp 125128. (2020).

25. Negmatov S.S., Gulyamov G., Abed N.S., Eshkobilov O.Kh., Methods for determining the coefficient of friction, temperature and magnitude of electrostatic charge in the friction zone of machine-building structural materials Composite and metal-polymer materials for various industries and agriculture, International Uzbek-Belarusian Scientific and Technical Conference. State Unitary Enterprise "Fan va tarakkiyot". Ташкент, 21-22-мау 2020y. pp 209-211. (2020)

26. Negmatov S.S., Gulyamov G., Abed N.S., Eshkobilov O.Kh., Sadikova M.M., Tukhtasheva M.N. Study of the influence of the main parameters of a disk tribometer and operating modes of machines on the coefficient of friction of epoxy composites when interacting with raw cotton, Composite materials, 2. Tashkent,. pp 82-85. (2020).

27. Eshkobilov O.Kh.... №FAP 00782 «Disc tribometer» Utility model patent. Agency of intellectual property of the republic of Uzbekistan. -Tashkent, (2012).

28. Eshkobilov O.Kh.... №FAP 01039 «Disc tribometer» Utility model patent. Agency of intellectual property of the republic of Uzbekistan. -Tashkent, (2015). 